Article

\title{
An Analysis of the Influence of Property Tax on Housing Prices in the Apulia Region (Italy)
}

\author{
Francesco Tajani ${ }^{1, *}$ (D), Pierluigi Morano ${ }^{1}$ (D), Carmelo Maria Torre ${ }^{1}$ and Felicia Di Liddo ${ }^{2}$ \\ 1 Department of Civil Engineering Sciences and Architecture, Polytechnic University of Bari, Via Orabona 4, \\ 70125 Bari, Italy; pierluigi.morano@poliba.it (P.M.); cartorre@yahoo.com (C.T.) \\ 2 Department of Architecture and Design, Sapienza University of Rome, Via Flaminia 359, 00196 Rome, Italy; \\ felicia.di@hotmail.it \\ * Correspondence: francescotajani@yahoo.it; Tel.: +39-080-596-38-24
}

Received: 11 July 2017; Accepted: 25 July 2017; Published: 27 July 2017

\begin{abstract}
In this research, the socio-economic determinants of housing market values have been examined, highlighting their respective contributions to the formation of the property prices and, in particular, verifying the property tax liability. The property tax is a factor that could determine, through modest fluctuations, the revival of the property demand, generating positive effects also on the construction sector, which has been currently affected by the negative real estate contingency. The functional correlations of housing prices with the main socio-economic variables considered (i.e., housing rents, household incomes, household consumptions, property taxes, population and mean population age) have been explained through an econometric analysis implemented with an innovative methodology that uses multi-objective genetic algorithms. The analysis is contextualized to the Apulia region in the South of Italy, and the population of the sample studied consists of 258 individuals, corresponding to the municipalities of the region. In particular, the data collected for each variable considered refer to two different moments, that is, the year 2011 and the year 2015, in order to take into account the fiscal tightening that has occurred in Italy in this period of time. The elaborations carried out have allowed us to enucleate interesting functional relationships between property prices and the explanatory variables considered.
\end{abstract}

Keywords: property tax; housing rents; incomes; housing prices; genetic algorithms; econometric analysis

\section{Introduction}

The financial crisis triggered by the US subprime mortgages in 2007 and that transformed into the current stagnation/recession of the major economies in Western countries has been the subject of a wide-ranging debate at the European level, concerning the economic measures to be taken to activate a rapid and peremptory revival [1]. The shadow banking mechanism linked to the many non-performing loans in bank accounts, which led the European Central Bank to promote a credit easing in 2015 aimed at supporting a highly fragile banking system, has highlighted the considerable differences between 'private' and 'public' debts, outlining that, when the difficulties of private credit become economically systematic or simply unsustainable at the political and social level, the weight falls on public debt, i.e., on citizens, through higher taxes that erode their available incomes. According to the data published by Eurostat [2], at the end of 2016, thirteen countries among the nineteen analyzed had a public debt above the $60 \%$ of their gross domestic product (GDP), i.e., the threshold set by the EU Stability Pact. Among them, Italy is affected by the highest public debt (2217.9 billion Euro), corresponding to a percentage of its GDP equal to $132.6 \%$, which places Italy at the top in Europe, i.e., it is second only to Greece, which is characterized by a percentage parameter equal to $179 \%$. According to Article 126 
of the EU Treaties and the 'Six Packs', i.e., the rule package for countries with excessive deficits, Italy must ensure a reduction in the stock of public debt at the average rate of a twentieth per year of the differential between the level in 2015 (132.1\%) and the European target of 60\%.

After the most significant increase in property taxation that dates back to the 1990s, in recent years, the Italian economic policy has been characterized, on the one hand, by an expansive spending review and, on the other hand, by fiscal policy initiatives that mainly concerned the level of taxation of private real estate assets. The total property taxes in Italy reached 52.3 billion Euro in 2015, a record level for its considerable size [3], taking into account that it constituted an increase of $38.7 \%$ compared with 2011, when property taxes amounted to 37.7 billion Euro. The increase in property taxation is mainly attributable to the introduction of the 'Unique Municipal Tax' (IMU), established by Decree Law No. 23/2011, which has resulted in a substantial increase in property tax.

In particular, according to Eurostat and Economic Cooperation and Development (OECD) data for the three-year period from 2011 to 2013, in Italy, the property tax as a percentage of GDP has increased from $0.6 \%$ in 2011 to $1.2 \%$ in 2013 [4]. Although this incidence is still lower than the weight on GDP that has been detected in other countries such as England (3.4\%) and France (2.6\%), the percentage increase described, which are essentially a doubling in nominal terms in Italy between 2011 and 2013, wherein property taxes have increased by $107.4 \%$, has been the highest in all European countries, with the exception of Hungary, where an almost similar increase has been detected $(+82.40 \%)$. In the rest of the European countries, the average increase in property tax for the three-year period from 2011 to 2013 was about $10 \%$ [3].

In addition to the most important components of the current global crisis (economic recession, unemployment, credit restrictions), the gradual increase in taxation may determine a significant impact on the Italian property market by contributing to the general selling price collapse and to a standby attitude of households and investors.

\section{Aim}

The topic of the present research concerns the framework outlined. With reference to the context of an Italian region, the aim of the paper is to examine the socio-economic determinants of housing market values i.e., the social and economic factors that influence the choices of the population of a specific territorial context and their interactions with the local built environment, highlighting their respective contribution to the formation of the property prices and, in particular, verifying the property tax liability. The effect of property tax on housing values is currently an important topic that in Italy deserves high attention from institutions, market investors, and real estate research. The property tax is a factor that could determine, through modest fluctuations, the revival of the property demand, generating positive effects also on the construction sector, which has been currently affected by the negative real estate contingency.

In Italy, there are currently no recent studies nor descriptive investigations relating to this topic. The present study is the first in the current literature that systematically deals with the quantification of the effects of $t$ property taxation on housing prices.

The functional correlations of housing prices with the main socio-economic variables considered (i.e., housing rents, household incomes, household consumptions, property taxes, population and mean population age) have been explained through an econometric analysis. In particular, an innovative methodology called Evolutionary Polynomial Regression (EPR) has been implemented, which uses multi-objective genetic algorithms to search those model expressions that simultaneously maximize the accuracy of the data and the parsimony of the final mathematical functions.

The analysis is contextualized to the Apulia region in the South of Italy, and the population of the sample studied consists of 258 individuals, corresponding to the municipalities of the region. The data collected for each variable considered refer to two different moments, which are 2011 and 2015, and the econometric analysis has been developed on the database obtained by making a ratio of the values of the homologous variables in the two time series detected. 
The ratio of the values of the homologous variables instead of, for example, the difference between the values allows us to make each variable adimensional, thus avoiding the influence that the numerical entity of each variable might have on the calibration of the econometric model.

The choice of analyzing the evolution of property prices generated by the variation of the socio-economic characteristics considered in the two years, 2011 and 2015, comes from the circumstance highlighted in the introduction, concerning the higher property tax burden that has occurred in Italy in this period time. Therefore, the research allows us to properly explain and interpret the possible influence of the property tax on changes in residential property values.

This research has been developed with reference to the sale of residential properties that, according to the Italian Revenue Agency [5], in 2017 represented 85.57\% of all transactions in the Italian property market.

The paper is structured as follows. In Section 3, the main researches in the international literature that have investigated the relationships between property taxes and property values are outlined. In Section 4, the variables considered are described and the main descriptive statistics related to the two starting databases (the years 2011 and 2015) and to the database used in the econometric analysis, which is obtained by making a ratio of the values of the homologous variables in the two starting databases considered, are analyzed. In Section 5, the methodology used is explained and the model obtained is illustrated; the specific statistic performances are shown, the empirical reliability of the functional relationships is verified, and the results are interpreted. Finally, in Section 6, the conclusions of the work are discussed.

\section{Background}

The correlations among socio-economic factors [6] and housing prices have been investigated in numerous studies [7-16]. In many of them, the developed analysis highlights that household income is among the parameters that most affect the variations of housing prices [17]. Taltavull de La Paz [18] has studied the relationship between residential prices and economic and demographic factors such as wages and migrations in the main Spanish cities, showing the significant correlation between price levels and households' waged income. Potepan [19] has shown that household income and construction costs are the most important factors that influence housing prices in U.S. metropolitan areas. Gibler et al. [20] have stressed, as regards the Finnish housing market, the predominance of income among the factors that have a positive influence on the decision to move house. Kryvobokov [21], comparing 81 regression models reported in the literature in order to determine, among the variables considered (demographic characteristics, income level of population, accessibility, planning and urban development characteristics, educational level of population, crime level, etc.), the most important attributes and to quantify their weights on the formation of the market value of residential and commercial properties, has demonstrated the significant role of the income in both market segments in Ukrainian cities.

Some studies have evaluated the influence on the price determined by sociological components such as the percentage of immigrants in the neighborhood and the large number of related crimes [22] or the weight of psychological factors such as the presence of neighboring homes recently requalified [23]. Glaeser et al. [24] have analyzed the increase of housing prices related to higher housing quality and construction costs in recent decades, determined by economic factors such as income growth and by behavioral evolution (e.g., improvements in the ability of homeowners to organize and influence local decisions, decreases in the ability to bribe regulations, greater tastes for amenities).

Several authors have highlighted the role of housing rents on the variations of property values, as well as fundamental factors such as personal income and population growth [25]. In general, high rents lead to an increased demand for housing in 'direct' use and, in a more marked form, for investment, resulting in a price increase [26-28].

In the reference literature, there are numerous studies that have analyzed the influence of property taxes on property values [29-33] and on urban developments [34-37]. In particular, Church [38], 
through a model of tax capitalization implemented on a sample of residential properties, has pointed out that the modification of property tax rates may have a significant impact on single family residential property values. Song and Zenou [39] have elaborated an econometric function on 448 urbanized areas, considering socio-economic variables such as the property tax rate measure, the population, the income, the agricultural rent, and the transportation expenditure and have shown that higher property taxes result in smaller cities and in the reduction of population density. Bartik [40] and Schmenner [41] have studied the influence of state taxes on the business location of a new manufacturing plant in the US. Hefferan and Boyd [42] have highlighted the need to take into account property taxation in the definition of appropriate valuation models of mass appraisal that may reflect the evolution of the economic system and meet contemporary changes.

Other authors have criticized the empirical generalization of the principle, according to which higher taxation generates reductive effects on property values [43], demonstrating the need to specify the assumptions of the implemented models $[44,45]$ and to differentiate the tax effects in various territorial contexts [46,47]. In fact, from a theoretical point of view, higher fiscal taxation should determine more public investments in local territory [48], which should therefore result in higher appreciation of local properties by potential buyers. Lang and Jian [49], analyzing the effects of legislative changes in Massachusetts, have shown that communities that were able to increase their property taxes more rapidly have been characterized by higher increases in their housing values in the period following the new regulations. Oates $[50,51]$ has pointed out that, in some situations, an increase in property taxation may result in an increase in rents to tenants, whereas it may have a modest impact on the market value of the properties.

\section{The Variables of the Model}

The population of the database consists of the 258 municipalities of the Apulia region in the South of Italy. Taking into account the functional relationships analyzed in the reference literature and the sources consulted for the data retrieval, the variables considered in the model for each municipality of the sample are as follows:

- the average unit housing price $(Y)$, expressed in $€ / \mathrm{m}^{2}$, that represents the dependent variable of the model;

- $\quad$ the average unit housing rent $(R)$, expressed in $€ / \mathrm{m}^{2}$ per month;

- the total property tax $(T)$ collected in each municipality, expressed in $€$;

- $\quad$ the taxable income per capita (I) in each municipality, expressed in Euro;

- $\quad$ the number of cars $(C)$ in circulation within the municipality;

- $\quad$ the number of motorcycles $(M)$ in circulation within the municipality;

- $\quad$ the resident population $(P)$, expressed as the number of inhabitants;

- $\quad$ the average age $(A)$ of the resident population, expressed in years;

The data on the variables unit housing prices $(Y)$ and unit housing rent $(R)$ have been collected through the analysis of the elaborations on the market transactions published by the Observatory of the Real Estate Market and Estimative Services of the Italian Revenue Agency [5]. The time series of the variable total property tax $(T)$ have been obtained by consulting the Italian Information System of the activities of Public Entities [52]. Finally, the database of the remaining socio-economic variables that considered income per capita $(I)$, number of cars $(C)$, number of motorcycles $(M)$, resident population $(P)$, and age $(A)$ has been generated through the elaboration of the statistical data published for the Italian municipalities [53].

It should be noted that, in this research, the variables number of cars $(C)$ and number of motorcycles $(M)$ have been used as proxies of the consumption appetite of the inhabitants of each municipality. Although the detection of more specific data representative of consumption appetite would have been more appropriate, the reference to the mentioned variables is related to the unavailability of alternative official information on household consumption at the municipal level. 
Tables 1 and 2 show, respectively, the main descriptive statistics of the variables considered in the two years taken as the references (2011 and 2015). The data analysis and the evolution of the values of the variables over the time period considered highlight that, in average terms, all the variables have been affected by modest variations, with the exception of the total property tax ( $T$ ), the average value of which has been more than doubled in the period from 2011 to 2015 (+105\%), from 2,030,187.14 Euro to 4,168,374.97 Euro. The highest average value variation has concerned the unit housing price $(Y)$, which has been characterized by a reduction of about $8 \%$ (from $905.74 € / \mathrm{m}^{2}$ to $830.49 € / \mathrm{m}^{2}$ ). Then, there are the income per capita $(I)$, which was affected by an increase of the average value from 13,648.52 Euro to $14,356.11$ Euro $(+5 \%)$; the average age $(A)$, the variation of which from 42.51 years to 43.83 years indicates a slight aging of the regional population $(+3 \%)$; the unit housing rent $(R)$, which has been characterized by a decrease in value from $3.27 € / \mathrm{m}^{2}$ per month to $3.18 € / \mathrm{m}^{2}$ per month $(-3 \%)$. The remaining variables, number of cars $(C)$, number of motorcycles $(M)$, and resident population $(P)$, have been affected by variations in average values of less than $1 \%$; from 9112.43 to 9001.41 for the number of cars $(C)$, from 1170.33 to 1160.10 for the number of motorcycles $(M)$, from $16,105.56$ to $16,267.38$ for the resident population $(P)$.

Table 1. Descriptive statistics of the variables of the sample in the year 2011.

\begin{tabular}{|c|c|c|c|c|}
\hline Variable & Mean & Standard Deviation & Levels/Intervals & Frequence [\%] \\
\hline \multirow{3}{*}{ Housing price $\left[€ / \mathrm{m}^{2}\right]$} & \multirow{3}{*}{905.74} & \multirow{3}{*}{431.90} & $<650$ & 31.6 \\
\hline & & & $650-1200$ & 49.0 \\
\hline & & & $>1200$ & 19.4 \\
\hline \multirow{3}{*}{ Housing rent $\left[€ / \mathrm{m}^{2} \times\right.$ month] } & \multirow{3}{*}{3.27} & \multirow{3}{*}{1.46} & $<2.5$ & 44.5 \\
\hline & & & $2.5-4.0$ & 29.6 \\
\hline & & & $>4$ & 25.9 \\
\hline \multirow{3}{*}{ Property tax $[€]$} & \multirow{3}{*}{$2,030,187.14$} & \multirow{3}{*}{$4,686,525.46$} & $<500,000$ & 35.2 \\
\hline & & & $500,000-1,000,000$ & 21.5 \\
\hline & & & $>1,000,000$ & 43.3 \\
\hline \multirow{3}{*}{ Income $[€]$} & \multirow{3}{*}{$13,648.52$} & \multirow{3}{*}{1991.99} & $<13,000$ & 38.4 \\
\hline & & & $13,000-15,000$ & 38.0 \\
\hline & & & $>15,000$ & 23.6 \\
\hline \multirow{3}{*}{ Number of cars [n.] } & \multirow{3}{*}{9112.43} & \multirow{3}{*}{$16,577.21$} & $<2500$ & 28.3 \\
\hline & & & $2500-7500$ & 36.9 \\
\hline & & & $>7500$ & 34.8 \\
\hline \multirow{3}{*}{ Number of motorcycles [n.] } & \multirow{3}{*}{1170.33} & \multirow{3}{*}{2728.30} & $<500$ & 47.4 \\
\hline & & & $500-1500$ & 37.2 \\
\hline & & & $>1500$ & 15.4 \\
\hline \multirow{3}{*}{ Population [n.] } & \multirow{3}{*}{$16,105.56$} & \multirow{3}{*}{$29,013.90$} & $<5000$ & 31.2 \\
\hline & & & $5,000-50,000$ & 62.7 \\
\hline & & & $>50,000$ & 6.1 \\
\hline \multirow{3}{*}{ Age [years] } & \multirow{3}{*}{42.51} & \multirow{3}{*}{2.52} & $<41$ & 27.9 \\
\hline & & & $41-44$ & 48.6 \\
\hline & & & $>44$ & 23.5 \\
\hline
\end{tabular}


Table 2. Descriptive statistics of the variables of the sample in the year 2015.

\begin{tabular}{|c|c|c|c|c|}
\hline Variable & Mean & Standard Deviation & Levels/Intervals & Frequence [\%] \\
\hline \multirow{3}{*}{ Housing price $\left[€ / \mathrm{m}^{2}\right]$} & \multirow{3}{*}{830.49} & \multirow{3}{*}{392.06} & $<650$ & 49.0 \\
\hline & & & $650-1200$ & 34.4 \\
\hline & & & $>1200$ & 16.6 \\
\hline \multirow{3}{*}{ Housing rent $\left[€ / \mathrm{m}^{2} \mathrm{x}\right.$ month $]$} & \multirow{3}{*}{3.18} & \multirow{3}{*}{1.51} & $<2.5$ & 49.4 \\
\hline & & & $2.5-4.0$ & 28.3 \\
\hline & & & $>4$ & 22.3 \\
\hline \multirow{3}{*}{ Property tax $[€]$} & \multirow{3}{*}{$4,168,374.97$} & \multirow{3}{*}{$9,424,887.46$} & $<500,000$ & 19.8 \\
\hline & & & $500,000-1,000,000$ & 16.2 \\
\hline & & & $>1,000,000$ & 64.0 \\
\hline \multirow{3}{*}{ Income $[€]$} & \multirow{3}{*}{$14,356.11$} & \multirow{3}{*}{2003.60} & $<13,000$ & 23.0 \\
\hline & & & $13,000-15,000$ & 42.2 \\
\hline & & & $>15,000$ & 34.8 \\
\hline \multirow{3}{*}{ Number of cars [n.] } & \multirow{3}{*}{9001.41} & \multirow{3}{*}{$16,092.92$} & $<2500$ & 28.3 \\
\hline & & & $2500-7500$ & 36.4 \\
\hline & & & $>7500$ & 35.3 \\
\hline \multirow{3}{*}{ Number of motorcycles [n.] } & \multirow{3}{*}{1160.10} & \multirow{3}{*}{2618.40} & $<500$ & 45.7 \\
\hline & & & 500-1500 & 38.9 \\
\hline & & & $>1500$ & 15.4 \\
\hline \multirow{3}{*}{ Population [n.] } & \multirow{3}{*}{$16,267.38$} & \multirow{3}{*}{$29,770.14$} & $<5000$ & 31.2 \\
\hline & & & $5000-50,000$ & 62.7 \\
\hline & & & $>50,000$ & 6.1 \\
\hline \multirow{3}{*}{ Age [years] } & \multirow{3}{*}{43.83} & \multirow{3}{*}{2.42} & $<41$ & 11.3 \\
\hline & & & $41-44$ & 43.3 \\
\hline & & & $>44$ & 45.4 \\
\hline
\end{tabular}

Table 3 shows the descriptive statistics for the variables used in the econometric analysis, obtained by the ratio $(\Delta)$ of the database values relative to the year 2015 and the respective values for the year 2011. It should be noted, in particular, that in the time period considered, for $73 \%$ of the sample, the variation of the total property $\operatorname{tax}(\Delta T)$ has been more than $+60 \%$, whereas the variations of the unit housing price $(\Delta Y)$ and of the unit housing rent $(\Delta R)$ outline reductions in the values, respectively, for $72 \%$ and for $54 \%$ of the sample. The variations of the income per capita $(\Delta I)$ and of the average age $(\triangle A)$ highlight that an increase, albeit rather modest (less than $+10 \%)$, has occurred for both the variables. Finally, if the variations of the variables number of cars $(\Delta C)$ and resident population $(\Delta P)$ are unimportant with respect the totality of the sample within a range between $-5 \%$ and $+5 \%$, the variation of the variable number of motorcycles $(\Delta M)$ is characterized by an increase of more than $+10 \%$ for the $18 \%$ of the sample analyzed.

Finally, the correlation analysis reported in Table 4 shows the absence of possible multicollinearity among the influencing factors considered. 
Table 3. Descriptive statistics of the variables used in the econometric analysis.

\begin{tabular}{|c|c|c|c|c|}
\hline Variable & Mean & Standard Deviation & Levels/Intervals & Frequence [\%] \\
\hline \multirow{3}{*}{$\Delta Y\left[€ / \mathrm{m}^{2}\right]$} & \multirow{3}{*}{0.92} & \multirow{3}{*}{0.18} & $<0.9$ & 42.0 \\
\hline & & & $0.9-1.0$ & 30.0 \\
\hline & & & $>1.0$ & 28.0 \\
\hline \multirow{3}{*}{$\Delta R\left[€ / \mathrm{m}^{2}\right.$ per month $]$} & \multirow{3}{*}{0.97} & \multirow{3}{*}{0.20} & $<0.9$ & 28.0 \\
\hline & & & $0.9-1.0$ & 26.0 \\
\hline & & & $>1.0$ & 46.0 \\
\hline \multirow{3}{*}{$\Delta T[€]$} & \multirow{3}{*}{2.05} & \multirow{3}{*}{0.74} & $<1.6$ & 27.0 \\
\hline & & & $1.6-2.2$ & 40.0 \\
\hline & & & $>2.2$ & 33.0 \\
\hline \multirow{3}{*}{$\Delta I[€]$} & \multirow{3}{*}{1.05} & \multirow{3}{*}{0.02} & $<1.04$ & 30.0 \\
\hline & & & $1.04-1.06$ & 36.0 \\
\hline & & & $>1.06$ & 34.0 \\
\hline \multirow{3}{*}{$\Delta C[\mathrm{n}]}$. & \multirow{3}{*}{0.99} & \multirow{3}{*}{0.02} & $<0.98$ & 24.0 \\
\hline & & & $0.98-1.00$ & 35.0 \\
\hline & & & $>1.00$ & 41.0 \\
\hline \multirow{3}{*}{$\Delta M[\mathrm{n}]}$. & \multirow{3}{*}{0.99} & \multirow{3}{*}{0.06} & $<0.98$ & 29.0 \\
\hline & & & $0.98-1.00$ & 43.0 \\
\hline & & & $>1.00$ & 28.0 \\
\hline \multirow{3}{*}{$\Delta P[$ n. $]$} & \multirow{3}{*}{1.01} & \multirow{3}{*}{0.02} & $<0.99$ & 32.0 \\
\hline & & & $0.99-1.01$ & 40.0 \\
\hline & & & $>1.01$ & 28.0 \\
\hline \multirow{3}{*}{$\Delta A$ [years] } & \multirow{3}{*}{1.03} & \multirow{3}{*}{0.01} & $<1.03$ & 44.0 \\
\hline & & & $1.03-1.04$ & 39.0 \\
\hline & & & $>1.04$ & 17.0 \\
\hline
\end{tabular}

Table 4. Correlation analysis of the variables used.

\begin{tabular}{cccccccc}
\hline Variable & $\boldsymbol{\Delta} \boldsymbol{R}$ & $\boldsymbol{\Delta} \boldsymbol{T}$ & $\boldsymbol{\Delta}$ & $\boldsymbol{\Delta} \boldsymbol{C}$ & $\boldsymbol{\Delta} \boldsymbol{M}$ & $\boldsymbol{\Delta} \boldsymbol{P}$ & $\boldsymbol{\Delta} \boldsymbol{A}$ \\
\hline $\boldsymbol{\Delta} \boldsymbol{R}$ & 1 & -0.005 & 0.059 & -0.033 & -0.051 & 0.004 & 0.005 \\
$\boldsymbol{\Delta} \boldsymbol{T}$ & -0.005 & 1 & 0.061 & -0.062 & 0.031 & -0.087 & -0.112 \\
$\boldsymbol{\Delta}$ & 0.059 & 0.061 & 1 & 0.040 & -0.080 & -0.114 & -0.101 \\
$\boldsymbol{\Delta} \boldsymbol{C}$ & -0.033 & -0.062 & 0.040 & 1 & 0.127 & 0.131 & 0.118 \\
$\boldsymbol{\Delta} \boldsymbol{M}$ & -0.051 & 0.031 & -0.080 & 0.127 & 1 & 0.062 & -0.025 \\
$\boldsymbol{\Delta} \boldsymbol{P}$ & 0.004 & -0.087 & -0.114 & 0.131 & 0.062 & 1 & -0.035 \\
$\boldsymbol{\Delta} \boldsymbol{A}$ & 0.005 & -0.112 & -0.101 & 0.118 & -0.025 & -0.035 & 1 \\
\hline
\end{tabular}

\section{The Method}

The econometric methodology implemented is a hybrid data-driven technique, called Evolutionary Polynomial Regression (EPR). This method can be considered a generalization of the stepwise regression that is linear with respect to regression parameters, but it is non-linear in the model structures [54]. Equation (1) shows a generic non-linear model structure of the methodology:

$$
Y=a_{0}+\sum_{i=1}^{n}\left[a_{i} \cdot\left(X_{1}\right)^{(i, 1)} \cdot \ldots \cdot\left(X_{j}\right)^{(i, j)} \cdot f\left(\left(X_{1}\right)^{(i, j+1)} \cdot \ldots \cdot\left(X_{j}\right)^{(i, 2 j)}\right)\right]
$$


where $n$ is the number of additive terms, $a_{i}$ is numerical parameters to be valued, $X_{i}$ is the candidate explanatory variables, $(i, l)$ with $l=(1, \ldots, 2 j)$ is the exponent of the $l$-th input within the $i$-th term in Equation (1), and $f$ is a function selected by the user among a set of possible mathematical expressions. The exponent $(i, l)$ is also selected by the user from a set of candidate values (real numbers).

The iterative investigation of model mathematical structures, implemented by exploring the combinations of exponents to be attributed to each candidate input of Equation (1), is performed through a population based strategy that employs a genetic algorithm, the individuals of which are constituted by the sets of exponents in Equation (1) and chosen by the user.

The accuracy of each equation returned is checked through its Coefficient of Determination (COD), defined in Equation (2):

$$
\mathrm{COD}=1-\frac{N-1}{N} \cdot \frac{\sum_{N}\left(y_{\text {estimated }}-y_{\text {detected }}\right)^{2}}{\sum_{N}\left(y_{\text {detected }}-\text { mean }\left(y_{\text {detected }}\right)\right)^{2}}
$$

where $y_{\text {estimated }}$ is the values of the dependent variable estimated by the methodology, $y_{\text {detected }}$ is the collected values of the dependent variable, and $N$ is the sample size under analysis. The fitting of a model is greater when the COD is close to the unit value.

The main advantage of the EPR method with respect to a classical econometric analysis (e.g., the hedonic price method) is that the genetic algorithm underlying the procedure does not require the exogenous definition of the mathematical expression and of the number of parameters that fit better the data collected, but the iterative process itself of the genetic algorithm returns the best solution. In this sense, the proposed method represents an evolution of the classical multiple regression that is considered during the iterative process of the genetic algorithm, and it is selected only if it constitutes a good solution, otherwise it is rejected in order to obtain the best performance of the final results. In particular, the EPR method allows us to apply an evolutionary multi-objective genetic algorithm as an optimization strategy based on the Pareto dominance criterion. These objectives are conflictual and aim at (1) the maximization of model accuracy through the satisfaction of appropriate statistical criteria for the verification of the equation; (2) the maximization of model's parsimony through the minimization of the number of terms $\left(a_{i}\right)$ of the equation; and (3) the reduction of the complexity of the model through the minimization of the number of the explanatory variables $\left(X_{i}\right)$ of the final equation.

Through the use of a Microsoft Office Excel add-in function, the optimization strategy defined above, based on the Pareto dominance criteria, allows us to obtain, at the end of the modelling phase, a set of model solutions (i.e., the Pareto front of optimal models) for the three objectives considered. In this way, a range of solutions is offered to the operator, from which it is possible to choose the most appropriate solution according to the specific needs, the knowledge of the phenomenon in analysis, and the type of experimental data used.

About the applications of the EPR method to the real estate field, the papers in the literature are very few and recent. In particular, Morano et al. [55] have used the EPR method for an analysis of the interdependencies of the property market with zonal and socio-economic variables in the municipalities of the region of Puglia (Italy). Tajani et al. have carried out a first experimentation of this technique with mass appraisal purposes, comparing it with the Artificial Neural Networks (ANN) method [56] and the hedonic price model [57]. There are not other applications to the property market, although the EPR method is characterized by interesting and unexplored potentialities.

\subsection{The Econometric Model Obtained}

The EPR method is implemented considering the base model structure reported in Equation (1) with no function $f$ selected. Each additive monomial term is assumed to be a combination of the inputs (i.e., the explanatory variables) raised to the proper exponents. 
Candidate exponents belong to the set $(-3 ;-2 ;-1 ;-0.5 ; 0 ; 0.5 ; 1 ; 2 ; 3)$ in order to have a wide range of solutions, among which the best compromise between performance statistics and the empirical reliability of the relationships between candidate inputs and the dependent variable can be defined.

The implementation of the EPR method has allowed us to obtain the following equation that links the selling prices to the independent variable considered:

$$
\begin{gathered}
\Delta Y=-237.3287 \cdot \Delta R^{0.5}+155.0251 \cdot \Delta R-31.2709 \cdot \Delta R^{2}+4.6446 \cdot \Delta R^{3}-27.8162 \cdot \frac{\Delta I^{0.5}}{\Delta R^{0.5}}+ \\
26.763 \cdot \Delta I^{0.5}-0.4142 \cdot \Delta M^{0.5} \cdot \Delta T^{0.5} \cdot \Delta R^{3}+0.33766 \cdot \Delta P \cdot \Delta A^{0.5} \cdot \Delta T^{0.5} \cdot \Delta I^{2} \cdot \Delta R+111.0029
\end{gathered}
$$

The performance indicators show a high statistical reliability for the model obtained; the COD is equal to $83.82 \%$; the Root Mean Square Error (RMSE), that is, the square root of the mean of the squared errors between the prices of the original sample and the values estimated through the model, is equal to 3.22\%; the Mean Absolute Percentage Error (MAPE), that is, the average percentage error between the detected prices and the values estimated, is equal to $2.45 \%$; and the Maximum Absolute Percentage Error (MaxAPE), that is the maximum percentage error between the detected prices and the values estimated through the model, is equal to $18.12 \%$.

\subsection{Interpretation of the Results}

The complexity of the model obtained in Equation (3) does not allow us to immediately check the empirical consistency of the signs that precede the independent variables with the real phenomena observed due to the presence of several variables in the same additive term and/or to the fact that the same variable appears in more additive terms but with opposed functional relationships.

Therefore, the functional relationship of the $i$-th independent variable with the variation of the housing prices $(\Delta Y)$ has been explained through an exogenous simplified approach that, instead of determining the partial derivative of the dependent variable with respect to the $i$-th variable, considers the values of the other variables in the model equal to the average values of the starting database and provides the analysis of the changes in value of the estimated variations of housing prices in correspondence with each $i$-th variable in the range of its corresponding sample values. The outputs of these elaborations are summarized in Figure 1.

The results obtained give rise to interesting considerations.

First of all, it should be noted that the econometric model in Equation (3) considers, in the explanation of the variations of the housing prices, all the input variables, with the exception of the variable relating to the variation of the number of cars $(\Delta C)$, characterized by values close to the unit value for the largest part of the sample analyzed, which means the absence of significant changes in the time period from 2011 to 2015. This circumstance indicates the lack of appreciable functional relationships between the variable number of cars and the unit housing prices $(\Delta Y)$, appropriately identified by the Pareto optimization algorithm implemented by the EPR method. The presence of the variable relating to the unit housing rents changes $(\Delta R)$ in almost all the terms of Equation (3) highlights the importance of this variable in the variation of the unit housing prices $(\Delta Y)$, as measured by the direct functional relationship shown in Figure 1. In particular, for variations of the variable $\Delta R$ below $100 \%$, i.e., for the situations where the unit housing rents are at most doubled from 2011 to 2015 , the changes in unit housing prices appear rather modest (maximum increase equal to $14.38 \%$ ), whereas the variable $\Delta Y$ exponentially grows (up to $+276 \%$ ) for variations of the variable $\Delta R$ between $100 \%$ and $180 \%$. This functional relationship exalts the role of the variable unit housing rent as a proxy for infrastructure facilities and services that concern with the locational characteristics of the municipalities in the sample being investigated, factors that, as noted in the reference literature, are the main determinants of the unit housing prices [58-63].

The graphical representations in Figure 1 show that the variations of the unit housing prices are positively correlated with changes in the income per capita $(\Delta I)$, characterized by a functional relationship that results in a maximum increase of the variable $\Delta Y$ equal to $+10.56 \%$ for a change 
equal to $+20 \%$ of the variable $\Delta I$. This correlation, identified by the model, confirms the thesis widely reported in the literature about the ordinary importance of variable income in explaining the variations in residential property prices [18-21].

The variables related to the variations of the residential population $(\Delta P)$ and the average age $(\Delta A)$ outline a positive correlation with the unit housing prices $(\Delta Y)$, but it is rather quantitatively low such that, for increments equal to $+10 \%$ of the explanatory variables mentioned, the unit housing prices increase respectively by $+5.80 \%$ and $+2.81 \%$ in the time period from 2011 to 2015 .
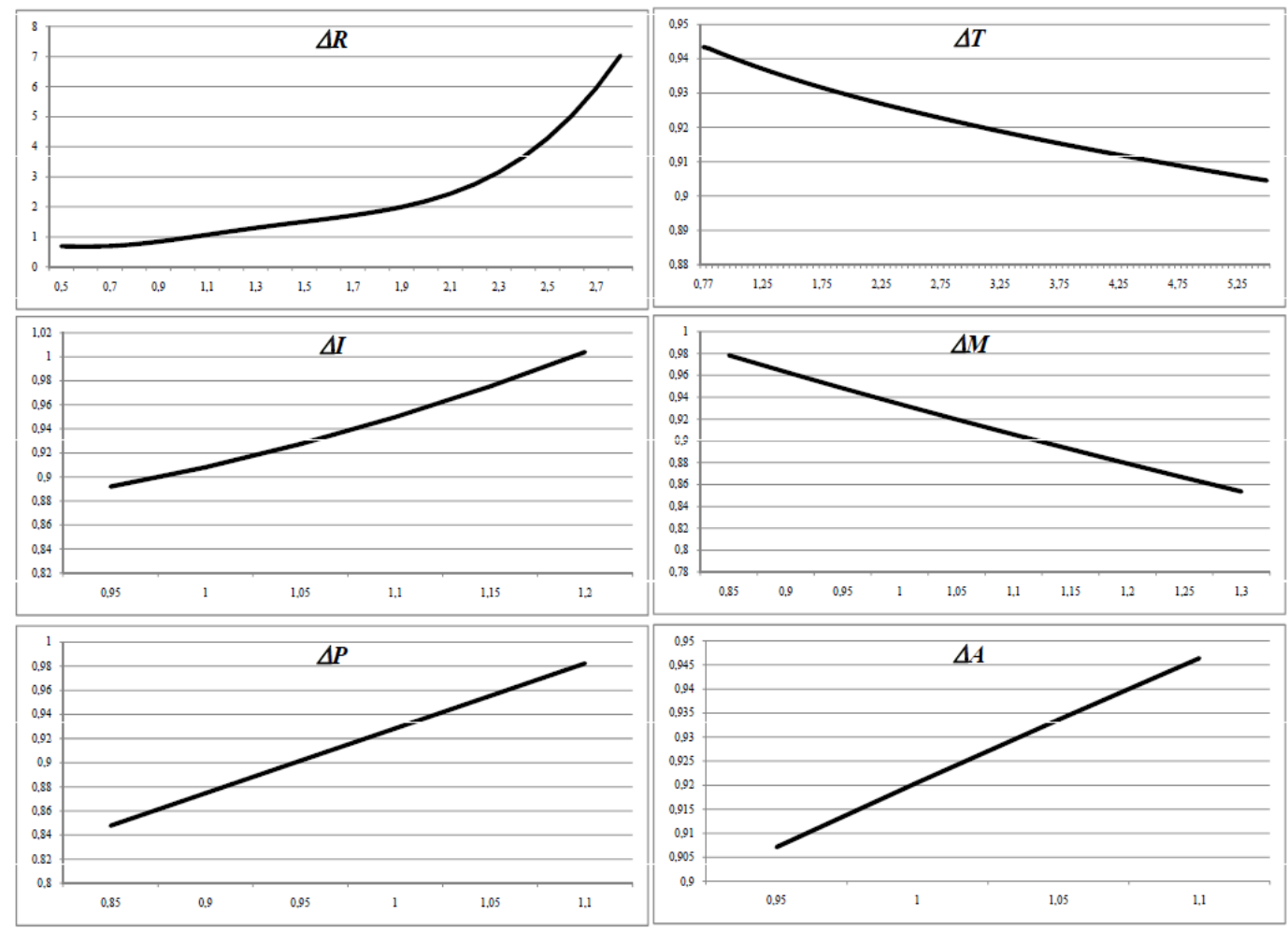

Figure 1. Evolutionary trend of the unit housing price variations depending on the variables of the model.

The model obtained points out a negative functional relationship between the variations of the number of motorcycles $(\Delta M)$ and the dependent variable $\Delta Y$ such that, for maximum variations of the independent variable $\Delta M$ equal to $+30 \%$, the unit selling prices decrease by $-8.57 \%$. Taking into account that the variation in the number of motorcycles represents, in the model obtained and for the time period from 2011 to 2015, the only variable that expresses the variation of the household expenditure in consumption, the variable for the variation of the number of cars has been endogenously eliminated by the optimization algorithm of the EPR method. Due to the inconsistency identified, the negative correlation found by the model is apparently in contrast to the usual expectation of rising property prices as consumption increases.

However, the analysis of the graph in Figure 2, where the evolution in the time period from 2011 to 2015 of the two variables relating to the variation in the number of motorcycles $(\Delta M)$ and the income per capita $(\Delta I)$ in the 258 municipalities of the study sample has been represented, gives an empirical basis to the inverse functional relationship identified by the EPR algorithm; the two independent variables tend to act in opposite ways, i.e., an increase in the income per capita corresponds to a decrease in the number of motorcycles. This correlation is confirmed by a study by the Italian Institute of Statistics [2], according to which, in 2015 in Italy, especially in the southern regions, a decrease in the available household income was followed by an increase in consumption. 


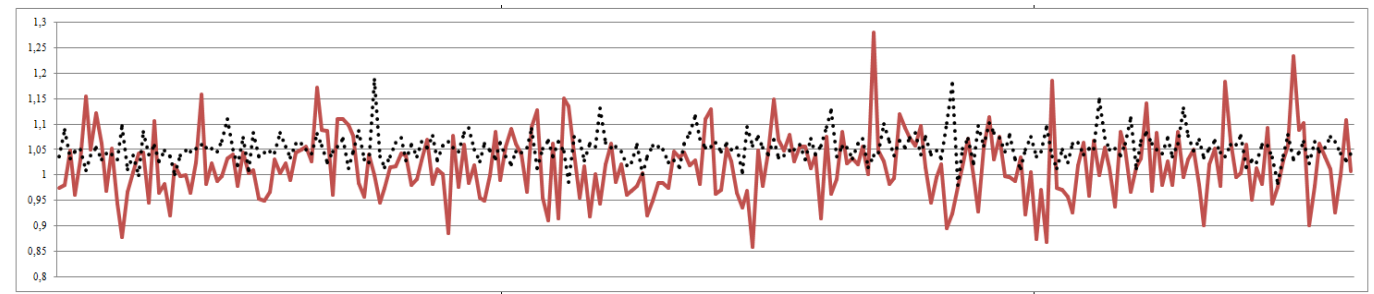

Figure 2. Values of the variables $\Delta M$ (continuous red line) and $\Delta I$ (broken black line) in the sample used.

Finally, the negative functional relationship between the variable relating to the changes in the total property $\operatorname{tax}(\Delta T)$ and the unit housing prices $(\Delta Y)$, shown in Figure 1, confirms the empirical evidence of the reduction in the housing demand resulting from an increase in the property taxation. It should be noted that, in the case analyzed, the influence of the variable relating to the variations of the total property tax identified by the EPR algorithm is rather low, resulting in a decrease in the unit housing prices equal to $-1.167 \%$ in the cases in which the total property tax increases by $100 \%$ and a maximum reduction equal to $-3.789 \%$ in extreme cases in which an increase in the total property tax exceeds $400 \%$.

However, the graph in Figure 3 shows an important correlation between the variable $\Delta T$ and the unit housing rents $(\Delta R)$, which, as seen above, is the most influential factor on the unit housing prices $(\Delta Y)$. For an average value of $\Delta T$ equal to 2.05 , which is the value detected for the study sample, up to an increase in the unit housing rents equal to $100 \%$, the variations of the unit housing prices $(\Delta Y)$ are rather modest, whereas, for variations of $\Delta R$ higher than $100 \%$, the functional relationship between $\Delta R$ and $\Delta Y$ becomes exponential; if $\Delta T$ was equal to 1 , i.e there was the absence of an increase in the property taxation in the time period from 2011 to 2015, the functional relationship between $\Delta R$ and $\Delta Y$ would be exclusively exponential, already with an increase equal to $129.5 \%$ of the unit housing prices for a positive variation equal to $+100 \%$ in the unit housing rents.

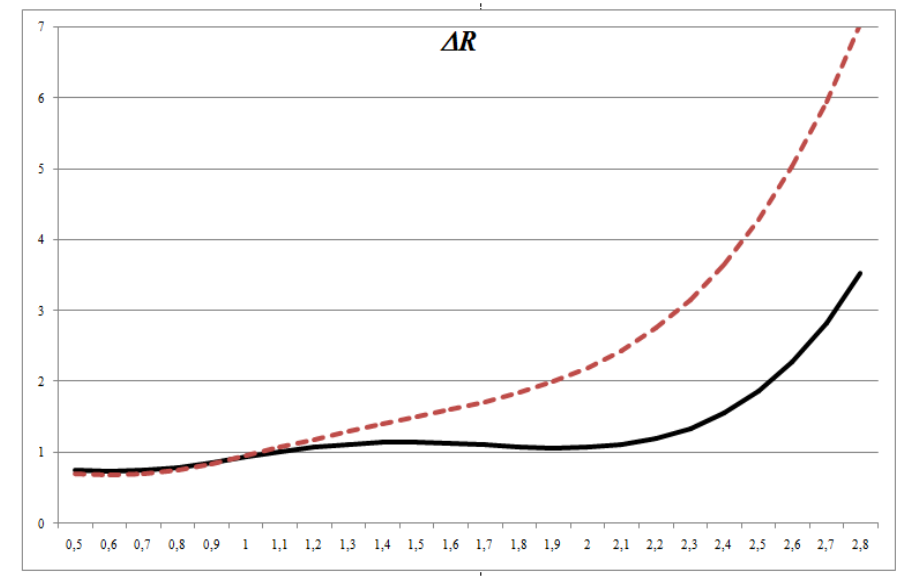

Figure 3. Functional relationships between the variable $\Delta R$ and the dependent variable $\Delta Y$ concerning a variation of the variable total property tax equal to $105 \%$ (continuous black line) and in the absence of variations of the variable total property tax (broken red line).

\section{Conclusions}

With reference to the Italian territorial context of the 258 municipalities of the Apulia region, in this paper, the analysis of the correlations among the main socio-economic factors and the housing market values has been performed. In particular, by considering the time series of the housing prices and the influencing variables selected (housing rents, household incomes, household consumptions, property taxes, population, and mean population age) and referring to two different moments, 2011 and 2015, an 
econometric analysis has been implemented in order to quantify the contribution of each explanatory variable and verify the property tax liability in the formation of housing prices. The spatial horizon (Italian region) and the time period (2011 to 2015) chosen for the analysis are not accidental, but they take into account, on the one hand, the historical preference of Italian citizens for housing investments, characterized by a net wealth invested in residential properties that is more than 4.570 billion Euro, i.e., more than half (56\%) of the net equity of the households and three times the national GDP [64]. On the other hand, the higher property tax burden that has affected Italy in the period from 2011 to 2015 has been considered. It is no coincidence that the analysis of the database obtained through the ratios of the variables' values between the two years considered shows that, in the municipalities of the Apulia region, the property tax has on average more than doubled, whereas there is a substantially unchanged situation for the other socio-economic variables of the model, with average values close to the unit value. The econometric analysis, developed using an innovative data-driven technique that employs a genetic algorithm to identify the functional expressions that define the Pareto front of optimal models in terms of statistical accuracy, has generated a model characterized by high reliability in terms of statistical performance indicators and by functional relationships between property prices and the explanatory variables, supported by the observation of the empirical phenomena and the results obtained by other research in the international literature.

The model obtained highlights a modest correlation between the property tax and housing prices. This phenomenon can be explained by the fact that, in Italy, property taxation, before the higher burden between 2011 and 2015, was rather low compared to the other European countries [65]; furthermore, higher property taxation did not lead to a substantial increase in the incidence of property taxes on the total tax revenues in Italy ( $+3.4 \%$ in 2012 ) compared to other European countries (e.g., $+3.1 \%$ in Spain, $+5.7 \%$ in France, $+11.8 \%$ in the United Kingdom) [4].

However, the model shows an indirect link between the property tax and housing prices; indeed, the increase in property tax significantly 'brakes' the impact with which housing rents, which constitute the most explanatory variable of housing prices, influence the rise in housing values.

It should be highlighted that the results obtained cannot be generalized to other geographical areas because of the specificity of the data and cannot be used to develop forecasts of market evolutions because of the unavailability of continuous data relating to a significant period. Nevertheless, when it is possible to define substantial time series as well as more specific data for the influencing factors considered, e.g., an indicator about the percentage of property taxation related to the property value and/or the number of properties concerning the total property taxes generated, a more appropriate measure of the consumption appetite of the population in each city can be analyzed. The logical path determined and the considerations developed can be a valid reference $[66,67]$.

Further insights may address the application of the econometric methodology proposed in other Italian and international territorial contexts in order to highlight the various functional relationships among the socio-economic factors, the property tax, and housing prices, and to support future welfare decisions as well as economic and fiscal policies.

Acknowledgments: The writers would like to thank Gianni Guerrieri, Central Director of the Observatory of the Real Estate Market and Estimative Services (Italian Revenue Agency), for his availability to provide the necessary real estate data for the analysis carried out and explained in the paper.

Author Contributions: The contribution is the result of the joint work of the authors. The paper must be attributed in equal parts to the authors.

Conflicts of Interest: The authors declare no conflict of interest.

\section{References}

1. Guarini, M.; Battisti, F. A model to assess the feasibility of public-private partnership for social housing. Buildings 2017, 7, 44. [CrossRef]

2. ISTAT. Rapporto Annuale 2015. La Situazione Del Paese. 2016. Available online: http:/ / www.istat.it (accessed on 1 May 2017). 
3. Impresa Lavoro Centro Studi. Available online: http://www.impresalavoro.org (accessed on 1 May 2017).

4. Osservatorio Mercato Immobiliare e Servizi Estimativi dell'Agenzia delle Entrate e dal Dipartimento delle Finanze. La Tassazione Immobiliare: Un Confronto Internazionale; 2015. Available online: http: / / www.agenziaentrate.gov.it (accessed on 1 May 2017).

5. Italian Revenue Agency. Available online: http://www.agenziaentrate.gov.it (accessed on 1 May 2017).

6. D'Acci, L. Measuring well-being and progress. Soc. Indic. Res. 2011, 104, 47-65. [CrossRef]

7. Beltratti, A.; Morana, C. International house prices and macroeconomic fluctuations. J. Bank. Financ. 2010, 34, 533-545. [CrossRef]

8. Berg, L. Prices on the second-hand market for Swedish family houses: Correlation, causation and determinants. Eur. J. Hous. Policy 2002, 2, 1-24. [CrossRef]

9. Capozza, D.R.; Hendershott, P.H.; Mack, C.; Mayer, C.J. Determinants of Real House Price Dynamics; NBER: Cambridge, MA, USA, 2002; p. 9262.

10. Conner, P.; Liang, Y.J. Income and cap rate effects on property appreciation. J. Portf. Manag. 2005, 31, 70-79. [CrossRef]

11. Rosato, P.; Giupponi, C.; Breil, M.; Fassio, A. Evaluation of urban improvement on the islands of the venice lagoon: A spatially-distributed hedonic-hierarchical approach. In Valuing Complex Natural Resource Systems: The Case of the Lagoon of Venice; FEE Mattei: Milan, Italy, 2006; pp. 75-98.

12. Rosato, P.; Alberini, A.; Zanatta, V.; Breil, M. Redeveloping derelict and underused historic city areas: Evidence from a survey of real estate developers. J. Environ. Plan. Manag. 2010, 53, 257-281. [CrossRef]

13. Semeraro, P.; Fregonara, E. The impact of house characteristics on the bargaining outcome. J. Eur. Real Estate Res. 2013, 6, 262-278. [CrossRef]

14. Taltavull de La Paz, P.; Gabrielli, L. Housing supply and price reactions: A comparison approach to Spanish and Italian Markets. Hous. Stud. 2015, 30, 1036-1063. [CrossRef]

15. Tsatsaronis, K.; Zhu, H. What Drives Housing Price Dynamics: Cross-Country Evidence. BIS Q. Rev. 2004, 65-78.

16. Wheaton, W. Real estate cycles: Some fundamentals. Real Estate Econ. 1999, 27, 209-230. [CrossRef]

17. Glaeser, E.L. Cities, Agglomeration and Spatial Equilibrium; Oxford University Press: Great Britain, UK, 2008.

18. Taltavull de La Paz, P. Determinants of housing prices in Spanish cities. J. Prop. Invest. Financ. 2003, 21, 109-135. [CrossRef]

19. Potepan, M.J. Explaining intermetropolitan variation in housing prices, rents and land prices. Real Estate Econ. 1996, 24, 219-245. [CrossRef]

20. Gibler, K.M.; Tyvimaa, T.; Kananen, J. The relationship between the determinants of rental housing satisfaction and considering moving in Finland. Prop. Manag. 2014, 32, 104-124. [CrossRef]

21. Kryvobokov, M. What location attributes are the most important for market value? Extraction of attributes from regression models. Prop. Manag. 2007, 25, 257-286.

22. Bowes, D.R.; Ihlanfeldt, K.R. Identifying the impacts of rail transit stations on residential property values. J. Urban Econ. 2001, 50, 1-25. [CrossRef]

23. Ding, C.; Simons, R.; Baku, E. The effect of residential investment on nearby property values: Evidence from Cleveland, Ohio. J. Real Estate Res. 2000, 19, 23-48.

24. Glaeser, E.L.; Gyourko, J.; Saks, R.E. Why have housing prices gone up? Am. Econ. Rev. 2005, 95, 329-333. [CrossRef]

25. Mikhed, V.; Zemčík, P. Do house prices reflect fundamentals? Aggregate and panel data evidence. J. Hous. Econ. 2009, 18, 140-149. [CrossRef]

26. Ayuso, J.; Restoy, F. House prices and rents: An equilibrium asset pricing approach. J. Empir. Financ. 2006, 13, 371-388. [CrossRef]

27. Manganelli, B.; Morano, P.; Tajani, F. House prices and rents. The Italian experience. WSEAS Trans. Bus. Econ. 2014, 11, 219-226.

28. Sivitanides, P.; Southard, J.; Torto, R.; Wheaton, W. The Determinants of Appraisal Based Capitalization Rates. Real Estate Financ. 2001, 18, 27-38.

29. Edelstein, R. The determinants of value in the Philadelphia housing market: A case study of the main line 1967-1969. Rev. Econ. Stat. 1974, 56, 319-328. [CrossRef]

30. Orr, L.L. The incidence of differential property taxes on urban housing. Natl. Tax J. 1968, 21, 253-262. 
31. Rosen, H.S.; Fullerton, D.J. A note on local tax rates, public benefit levels, and property values. J. Political Econ. 1977, 85, 433-440. [CrossRef]

32. Yinger, J.; Bloom, H.S.; Boersch-Supan, A. Property Taxes and House Values: The Theory and Estimation of Intrajurisdictional Property Tax Capitalization; Academic Press: San Diego, CA, USA, 2016.

33. Wales, T.J.; Wiens, E.G. Capitalization of residential property taxes: An empirical study. Rev. Econ. Stat. 1974, 56, 329-333. [CrossRef]

34. Brueckner, J.K.; Kim, H.A. Urban sprawl and the property tax. Int. Tax Public Financ. 2003, 10, 5-23. [CrossRef]

35. Papke, L.E. Tax policy and urban development: Evidence from the Indiana enterprise zone program. J. Public Econ. 1994, 54, 37-49. [CrossRef]

36. Polinsky, A.M.; Rubinfeld, D.L. The long-run effects of a residential property tax and local public services. J. Urban Econ. 1978, 5, 241-262. [CrossRef]

37. Simon, H.A. The incidence of a tax on urban real property. Q. J. Econ. 1943, 57, 398-420. [CrossRef]

38. Church, A.M. Capitalization of the effective property tax rate on single family residences. Natl. Tax J. 1974, 27, 113-122.

39. Song, Y.; Zenou, Y. Property tax and urban sprawl: Theory and implications for US cities. J. Urban Econ. 2006, 60, 519-534. [CrossRef]

40. Bartik, T.J. Business location decisions in the United States: Estimates of the effects of unionization, taxes, and other characteristics of states. J. Bus. Econ. Stat. 1985, 3, 14-22. [CrossRef]

41. Schmenner, R.W. City Taxes and Industry Location. In Proceedings of the Annual Conference on Taxation Held under the Auspices of the National Tax Association-Tax Institute of America; National Tax Association: Washington, DC, USA, 1973; Volume 66, pp. 528-532.

42. Hefferan, M.J.; Boyd, T. Property taxation and mass appraisal valuations in Australia-Adapting to a new environment. Prop. Manag. 2010, 28, 149-162. [CrossRef]

43. Sirmans, S.; Gatzlaff, D.; Macpherson, D. The History of Property Tax Capitalization in Real Estate. J. Real Estate Lit. 2008, 16, 327-344.

44. Meadows, G.R. Taxes, spending, and property values: A comment and further results. J. Political Econ. 1976, 84, 869-880. [CrossRef]

45. Palmon, O.; Smith, B.A. A new approach for identifying the parameters of a tax capitalization model. J. Urban Econ. 1998, 44, 299-316. [CrossRef]

46. Hyman, D.N.; Pasour, E.C., Jr. Property tax differentials and residential rents in North Carolina. Natl. Tax J. 1973, 26, 303-307.

47. King, A.T. Estimating property tax capitalization: A critical comment. J. Political Econ. 1977, 85, 425-431. [CrossRef]

48. Pollakowski, H.O. The effects of property taxes and local public spending on property values: A comment and further results. J. Political Econ. 1973, 81, 994-1003. [CrossRef]

49. Lang, K.; Jian, T. Property taxes and property values: Evidence from Proposition 212. J. Urban Econ. 2004, 55, 439-457. [CrossRef]

50. Oates, W.E. The effects of property taxes and local public spending on property values: An empirical study of tax capitalization and the Tiebout hypothesis. J. Political Econ. 1969, 77, 957-971. [CrossRef]

51. Oates, W.E. The effects of property taxes and local public spending on property values: A reply and yet further results. J. Political Econ. 1973, 81, 1004-1008. [CrossRef]

52. Italian Information System of the activities of Public Entities. Available online: http://www.siope.it (accessed on 1 May 2017).

53. Elaboration of the Statistical Data Published for the Italian Municipalities. Available online: http:/ / www. comuni-italiani.it (accessed on 1 May 2017).

54. Giustolisi, O.; Savic, D. Advances in data-driven analyses and modelling using EPR-MOGA. J. Hydroinform. 2009, 11, 225-236. [CrossRef]

55. Morano, P.; Tajani, F.; Locurcio, M. Land use, economic welfare and property values. An analysis of the interdependencies of the real estate market with zonal and socio-economic variables in the municipalities of the Region of Puglia (Italy). Int. J. Agric. Environ. Inf. Syst. 2015, 6, 16-39. [CrossRef] 
56. Tajani, F.; Morano, P.; Locurcio, M.; D’Addabbo, N. Property Valuations in Times of Crisis. Artificial neural Networks and Evolutionary Algorithms in Comparison. In Proceedings of the Annual Conference on Computational Science and Its Applications, LNCS; Springer International Publishing: Cham, Switzerland, 2015; Volume 9157 (part III), pp. 194-209.

57. Tajani, F.; Morano, P.; Locurcio, M.; Torre, C.M. Data-driven techniques for mass appraisals. Applications to the residential market of the city of Bari (Italy). Int. J. Bus. Intell. Data Min. 2016, 11, 109-129. [CrossRef]

58. Des Rosiers, F.; Lagana, A.; TheÂriault, M.; Beaudoin, M. Shopping centers and house values: An empirical investigation. J. Prop. Valuat. Invest. 1996, 14, 41-63. [CrossRef]

59. Grieson, R.E.; White, J.R. The existence and capitalization of neighbourhood externalities: A reassessment. J. Urban Econ. 1989, 25, 68-76. [CrossRef]

60. Guntermann, K.L.; Colwell, P.F. Property values and accessibility to primary schools. Real Estate Apprais. Anal. 1983, 49, 62-68.

61. Hickman, E.P.; Gaines, J.P.; Ingram, F.J. The influence of neighbourhood quality on residential values. Real Estate Apprais. Anal. 1984, 50, 36-42.

62. Waddell, P.; Berry, B.J.L.; Hoch, I. Residential property values in a multinodal urban area: New evidence on the implicit price of location. J. Real Estate Financ. Econ. 1993, 7, 117-141. [CrossRef]

63. Walden, M. Magnet schools and the differential impact of school quality on residential property values. J. Real Estate Res. 1990, 5, 221-230.

64. Banca D'italia. Available online: http://www.bancaditalia.it (accessed on 1 May 2017).

65. Garnier, G.; Gyorgy, E.; Heineken, K.; Mathe', M.; Puglisi, L.; Ruà, S.; Skonieczna, A.; Van Mierlo, A. A wind of change? Reforms of Tax Systems since the launch of Europe 2020. Reflets et Perspectives De La Vie Économique 2014, 53, 75-111. [CrossRef]

66. Del Giudice, V.; De Paola, P.; Cantisani, G.B. Rough Set Theory for real estate appraisals: An application to Directional District of Naples. Buildings 2017, 7, 12. [CrossRef]

67. Del Giudice, V.; De Paola, P.; Cantisani, G.B. Valuation of real estate investments through Fuzzy Logic. Buildings 2017, 7, 26. [CrossRef]

(C) 2017 by the authors. Licensee MDPI, Basel, Switzerland. This article is an open access article distributed under the terms and conditions of the Creative Commons Attribution (CC BY) license (http:/ / creativecommons.org/licenses/by/4.0/). 